\title{
AVALIAÇÃO DO CONHECIMENTO DE ALUNOS DO CICLO BÁSICO SOBRE RECICLAGEM
}

\author{
Henrique Amaral Marcotto ${ }^{1}$ \\ Amarildo Antonio Tessaro ${ }^{2}$ \\ Alessandra Buss Tessaro ${ }^{3}$
}

Resumo: Buscando avaliar se os alunos de $8^{\text {a }}$ série estão tendo um aprendizado adequado com relação à reciclagem, realizou-se um estudo em dois Colégios Estaduais do município de Francisco Beltrão - PR. Os Colégios foram identificados como Colégio A e B. Foi aplicado um questionário contendo oito questões em cada colégio visitado. A avaliação efetuada nas escolas sobre o conhecimento dos alunos a respeito de reciclagem mostrou que o estudo sobre o tema ocorre nas escolas, mas necessita ser melhorado. Os resultados também apontaram que a disciplina de Educação Ambiental é estudada dentro de outras disciplinas. Deve-se priorizar mais atividades práticas referentes ao tema, introduzindo trabalhos fora da sala de aula, entre outras possibilidades.

Palavras-chave: Reciclagem; Educação Ambiental; Coleta Seletiva;

${ }^{1}$ União do Ensino do Sudoeste do Paraná. E-mail: ikeamaralm@hotmail.com.

${ }^{2}$ União do Ensino do Sudoeste do Paraná. E-mail: amarildo@unisep.edu.br.

${ }^{3}$ Universidade Federal de Pelotas. E-mail: alessandrabuss@gmail.com. 


\section{Introdução}

O futuro de todas as espécies depende do equilíbrio do meio ambiente. Sem uma relação harmônica e equilibrada entre o ser humano e a natureza, não há como assegurar a sadia qualidade de vida no presente e resta comprometida a existência das futuras gerações (GOMES, 2006).

Diante disso, percebe-se a necessidade de se buscar uma nova ética, regida por um sentimento de pertencimento mútuo entre todos os seres. A ética sempre esteve preocupada com as questões de existência do homem, mas agora deve voltar-se, principalmente, para a sua inter-relação com o planeta. De modo que é necessária a construção de uma ética ambiental voltada ao futuro, para que o direito fundamental ao meio ambiente ecologicamente equilibrado possa ser assegurado às presentes e futuras gerações. Deve-se buscar a consciência ecológica através da educação ambiental fundamentada na ética ambiental (SIRVINSKAS, 2002).

A educação ambiental é definida pelo art. $1^{\circ}$ da Lei 9.795/99 como o conjunto de processos por meio dos quais o indivíduo e a coletividade constroem valores sociais, conhecimentos, habilidades, atitudes e competências voltadas para a conservação do meio ambiente, bem de uso comum do povo, essencial à sadia qualidade de vida e sua sustentabilidade. A própria Constituição Federal estabelece que cabe ao Poder Público "promover a educação ambiental em todos os níveis do ensino e a conscientização pública para a preservação do meio ambiente". A educação ambiental deve estar presente em todos os níveis e modalidades do ensino, e cabe ao Poder Público a fiscalização de sua aplicação (RODRIGUES, 2004).

Claramente uma das atividades necessárias para se ter um desenvolvimento sustentável está relacionado ao gerenciamento eficiente dos resíduos que a sociedade gera. A população brasileira gera, diariamente, em torno de 126 mil toneladas de lixo de consumo, excluindo-se aqui dejetos industriais e empresariais. Não fosse o trabalho dos catadores, todo esse volume de material acabaria destinado integralmente aos aterros sanitários e lixões (OLIVEIRA, 2009).

Diante da crise ambiental vivenciada já há algum tempo, surgiu a necessidade de propor ações que pudessem sensibilizar a população, a consciência e a necessidade de conservar os recursos naturais, tendo a Educação Ambiental como um importante instrumento e alternativa. Assim, a Educação Ambiental (EA) assume um papel importante para a promoção do desenvolvimento sustentável, uma vez que aumenta a capacidade das pessoas em abordar questões relacionadas à problemática ambiental, devendo, particularmente, a escola ser palco principal de discussões na sociedade, com o propósito de promover mudanças que garantam a melhoria das condições de vida (CRISÓSTOMO, 2011).

Para assumir seu caráter transformador, a EA fornece instrumentos

para a sociedade, de modo a ampliar as discussões e ações concretas referentes às questões ambientais, sobretudo no âmbito das escolas, Revbea, São Paulo, V. 9, № 2: 451-460, 2014. 
almejando uma população mais consciente e educada para tais questões (ALMEIDA; BICUDO; BORGES, 2004). É essencial que os futuros cidadãos aprendam a gerenciar de forma eficiente o resíduo gerado, sendo a escola 0 melhor meio para ensiná-los. E, quando não for possível evitar a geração, que os alunos saibam implementar ações para que este resíduo gere o menor impacto possível ao meio ambiente.

A maneira mais simples para gerar menor impacto é a separação dos resíduos por meio de processos como a reciclagem, que além de diminuir o material depositado na natureza, também ajuda a não desperdiçar recursos naturais. Tomando-se por base que a educação ambiental existe e é implementada de forma rotineira nas escolas, e que a reciclagem é extremamente importante, faz-se necessário avaliar se o processo de ensino/aprendizagem é eficiente, visto que os índices de coleta de lixo separado são relativamente baixos.

Este índice pode ser fruto de alguma falha no processo de ensino, onde as pessoas podem não ter pleno conhecimento de como separar o lixo e quais materiais são recicláveis. Os resíduos sólidos urbanos são um dos maiores problemas na sociedade atual e na gestão dos municípios, que surgiram e se intensificaram com o processo de urbanização, necessitando que esses sejam reduzidos. Uma das melhores maneiras para controlar essa geração exagerada é ensinando a correta destinação através de aulas de Educação Ambiental. O objetivo deste trabalho é avaliar o conhecimento dos alunos referente à reciclagem dos resíduos.

\section{Metodologia}

A metodologia de investigação trata-se de uma pesquisa de campo como abordagem qualitativa utilizando como suporte do referencial teórico de livros, dissertações, teses, artigos e textos disponíveis na Internet. A coleta de dados ocorreu por meio de questionário aos alunos da $8^{\mathrm{a}}$ série de dois Colégios Estaduais de Francisco Beltrão/PR. Os colégios foram identificados como Colégio $A$ e Colégio $B$. Foram aplicados 24 questionários no Colégio $A$ e 29 no Colégio $B$, totalizando 53 questionários.

O município de Francisco Beltrão possui 11.680 acadêmicos no ensino fundamental, isto é de $1^{\underline{a}}$ a $8^{\underline{a}}$ ou $9^{\underline{a}}$ série, distribuídos em 42 instituições de ensino estaduais, municipais e particulares (IPARDES, 2011).

O questionário foi aplicado aos alunos dos Colégios Estaduais de Francisco Beltrão com questões envolvendo coleta seletiva, se existia interdisciplinaridade relacionada ao assunto; buscando avaliar seus conhecimentos em Educação Ambiental.

O questionário montado procurou ser sucinto e com poucas questões sendo a maioria de múltipla escolha, tentando apresentar um aspecto visual atrativo com o uso de muitas imagens e com poucas questões dissertativas. Buscou-se por meio deste formato de questionário que a atividade não se

revista brasileira educação ambiental 
tornasse cansativa para os alunos. O questionário aplicado aos alunos possui 8 questões, sendo 5 objetivas e 3 dissertativas.

Os questionários aplicados possibilitaram uma maior compreensão quanto ao grau de conhecimento dos alunos em relação à Reciclagem.

\section{Resultados e Discussões}

A primeira questão buscava avaliar os conhecimentos teóricos relacionados à reciclagem. Em torno de $54 \%$ dos alunos respondeu ao item $B$ "reaproveitar materiais beneficiados como matéria-prima para um novo produto", mostrando que em algum momento estes tiveram contato com o conceito correto de reciclagem. Isto independente da forma como a escola trabalha com relação ao assunto da reciclagem. A segunda alternativa mais votada $(25 \%)$, em ambas as escolas, foi a C, que corresponde a uma conceituação de coleta seletiva e não de reciclagem (Figura 1). Deve-se alertar aos alunos que o processo de reciclagem não é somente separar materiais; a separação é apenas o início do processo para ocorrer a reciclagem. Ainda podemos ver que parte dos alunos confunde reciclagem com reutilização ou reaproveitamento de materiais, que são outras formas de não destiná-los aos aterros sanitários, diminuindo o impacto ao meio ambiente que estes podem causar.
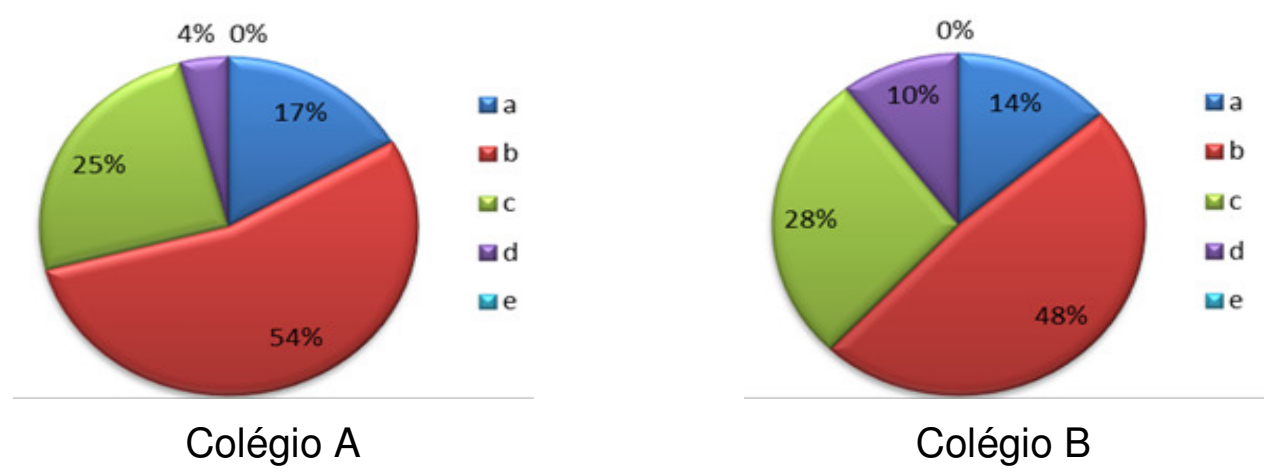

Figura 1: Resposta à Questão 1.

Contudo, a reciclagem não deve ser vista unicamente como a principal solução para o lixo. Ela é tão-somente uma atividade econômica que deve ser encarada como um elemento dentro de um conjunto de soluções ambientais. Para GRIPPI (2001, p.74), apenas "separar o lixo sem um mercado é enterrar em separado". Ou seja, a separação de materiais do lixo aumenta a oferta de materiais recicláveis. Entretanto, se não houver demanda por parte da sociedade ou do mercado, o processo é interrompido e os materiais podem abarrotar os depósitos ou serem enterrados em outro lugar. 
A Questão 2 do questionário aplicado buscava avaliar se os acadêmicos sabiam distinguir entre as formas existentes para evitar o descarte de materiais. Estes quando questionados apresentam dúvidas em distinguir o que é o processo de reutilização, reaproveitamento e reciclagem. A alternativa mais marcada foi a alternativa A (Figura 2), que corresponde ao reaproveitamento de materiais. De maneira geral não distinguir reutilização e reaproveitamento não seria algo tão prejudicial no processo, mas a confusão que foi verificada nos conceitos de reutilização com reciclagem, sim. Onde para a maioria dos alunos, reutilizar foi confundido com o processo de reciclagem.
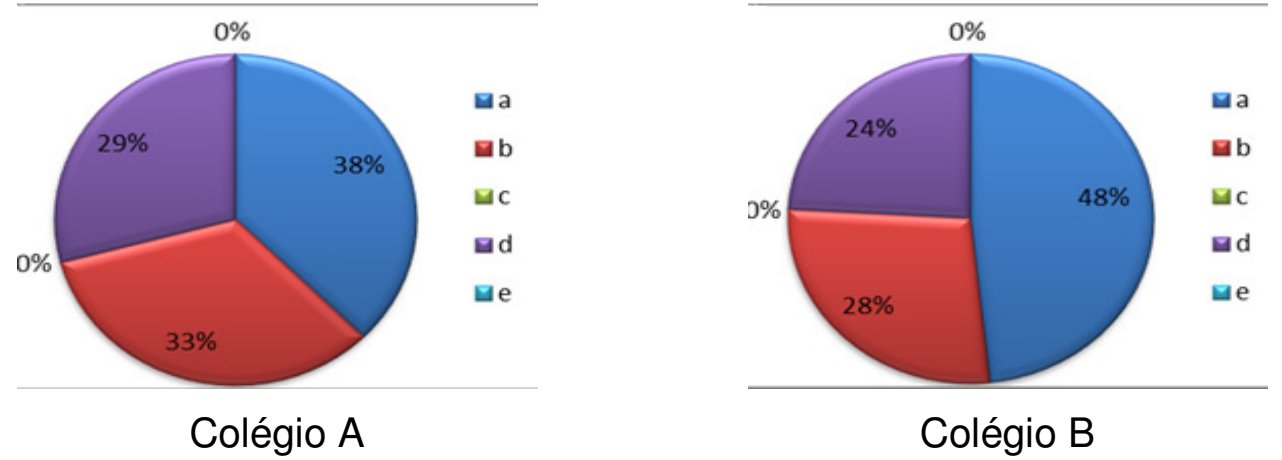

Figura 2: Resposta à Questão 2.

De acordo com Rebello e Vieira (2011), reutilizar é o mesmo que encontrar soluções criativas para estender a vida útil de um produto, usando-o em outro contexto, diferente daquele em que foi projetado. Reaproveitar também se apropria da reutilização, porém com uma diferença essencial: a matéria-prima que antes permanecia imutável em reutilizar, agora terá necessariamente de ser modificada manualmente. Um sinônimo do reaproveitamento é a customização, em outras palavras, a agregação criativa reduzindo perdas e refugos ou colocando novos valores e utilidades para um objeto. Quanto a reciclar, pode-se afirmar que suas características enfatizam a necessidade de inserir novamente num ciclo industrial ou reprocessar. Sendo a "re-ciclagem", ou o novo ciclo industrial, a principal diferença entre o reaproveitar.

É fundamental discernirmos o que podemos ou não reciclar para a correta gestão dos resíduos sólidos urbanos.

Encerrando a abordagem sobre conceitos que estão envolvidos sobre a reciclagem, a Questão 3 questionou os acadêmicos sobre o que seria a coleta seletiva. Em ambas as escolas, mais de 50\% dos alunos acertaram a questão cuja resposta era "Descartar os materiais de forma separada no lixo" (Figura 3). Nesta questão era esperado um maior acerto, visto que a coleta seletiva devia ser algo mais comum para os alunos e que estes deveriam saber que esta é a separação do lixo que deveriam realizar em casa. 


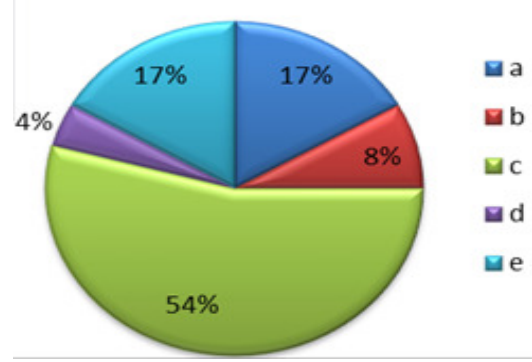

Colégio A

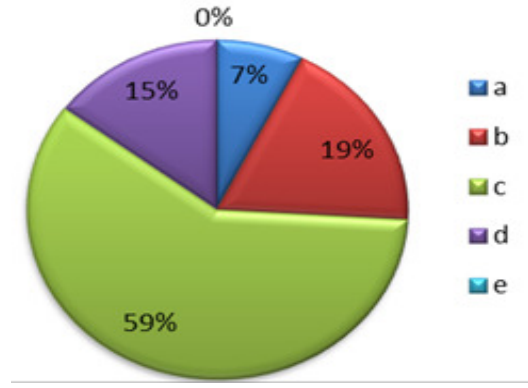

Colégio B

Figura 3; Resposta à Questão 3.

Um dos destinos para os resíduos sólidos domiciliares é a coleta seletiva, que é a segregação dos resíduos nas categorias de papel, plástico, vidro e metal, que depois de separados, são levados a indústrias de reciclagem (SCHALCH et al., 2002). Esta separação pode ser realizada nas próprias casas e encaminhada para seu destino final. Não associar a coleta seletiva à separação do lixo pode estar relacionado ao fato que e separação dos resíduos não é realizada nas casas dos alunos. Contudo avaliar se a separação do lixo é realizada ou não pelos alunos não foi o enfoque deste trabalho, mas sim se possuem conhecimento sobre reciclagem. Da mesma forma que já discutido pela Questão 1 verifica se novamente que as crianças não estão conseguindo distinguir conceitos de programas, pois estão relacionando o programa de coleta seletiva aos conceitos de reaproveitamento, reciclagem e reutilização respectivamente.

A Questão 4 buscava avaliar os conhecimentos mais específicos sobre quais materiais podem ser reciclados. $O$ vidro foi o material que menos acertos obteve (Figura 4). No Colégio A 50\% dos alunos erraram enquanto no Colégio B obteve aproximadamente $25 \%$ de erro. Podemos relacionar esse erro referente ao vidro ser, de forma geral, o material menos reciclado entre os quatro apresentados aos alunos, isto porque os catadores não possuem interesse por este material, devido ao seu elevado peso e volume.

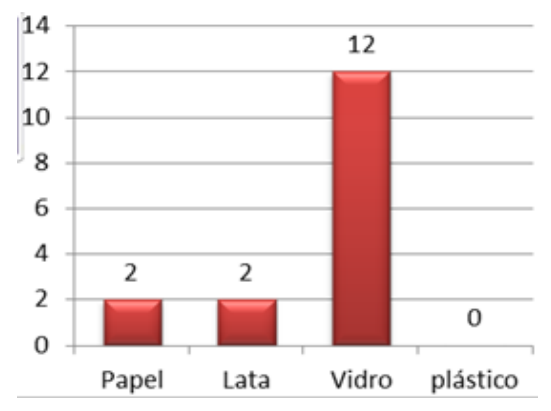

Colégio A

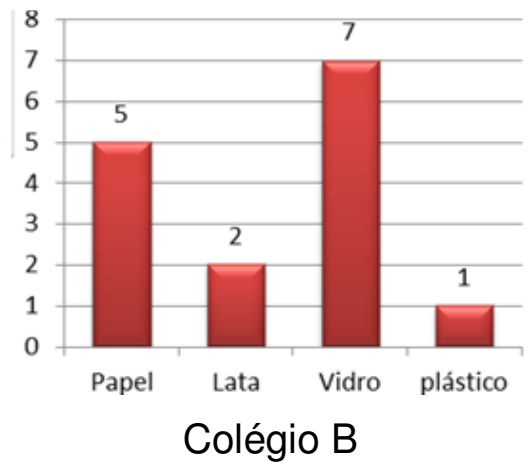

Figura 4: Número de erros da resposta à Questão 4. 
A correta separação destes resíduos depende de sua classificação, assim Brasil (2006) por meio de suas normas e resoluções classifica-os conforme seus riscos ao meio ambiente e a saúde, também como em função da natureza e origem. A NBR 10004/2004 classifica os resíduos em duas classes. A classe I engloba os resíduos perigosos, que possuem características químicas, físicas e biológicas que podem causar riscos à saúde e ao meio ambiente. A classe II comporta os resíduos não perigosos que são subdivididos em classe II A - podem ter as propriedades de biodegrabilidade, combustabilidade ou solubilidade em água - e classe II B - que não apresentam nenhum componente solubilizado. Em relação à origem e natureza, segundo Brasil (2006), os resíduos foram agrupados em dois grandes grupos: resíduos sólidos urbanos - domésticos ou residenciais; comerciais e públicos - e resíduos especiais - industriais; da construção civil, radioativos, de portos, aeroportos e terminais rodoferroviários, agrícolas e de serviços de saúde.

A Questão 5 teve finalidade de testar os conhecimentos específicos quanto a separação do lixo e abordou as cores das lixeiras dos mesmos 4 grupos principais avaliados na Questão 4. A separação dentro destes 4 grupos (papel, vidro, metal e plástico) mais uma para os demais materiais é a mais usual em locais com um sistema adequado de separação.

Para isto foi disponibilizado na questão um figura com 5 lixeiras e abaixo destas um número com os grupos de materiais recicláveis que deveriam ser colocados abaixo das suas respectivas lixeiras.

Ocorreu apenas um acerto em ambos os colégios (Figura 5). Isso demonstra falha dentro do programa de Educação Ambiental nos colégios, já que a inclusão de um sistema adequado de separação de lixo nas escolas é uma exigência da Secretaria de Educação do Estado.

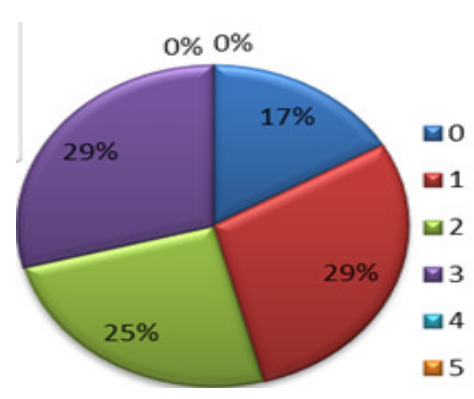

Colégio A

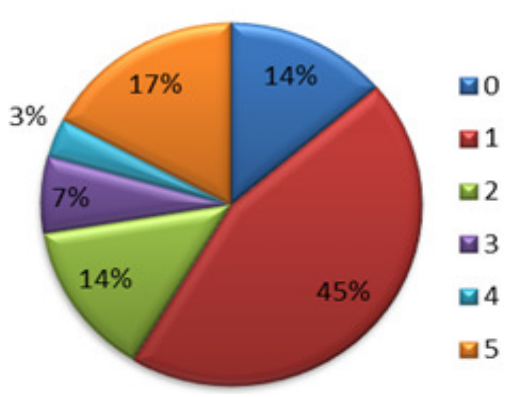

Colégio B

Figura 5: Resposta à Questão 5. 
Contudo observamos que dentro de um contexto geral poucos alunos sabem realmente o sistema de cores dos recicláveis. Segundo Monteiro (2001: 115), a Resolução CONAMA oㅡ 275, estabelece um sistema de cores para diferenciar os resíduos, para facilitar o trabalho de seleção dos mesmos. Nesse caso as fontes geradoras teriam maior facilidade na identificação do lixo para a coleta seletiva (Tabela 1).

Tabela 1: Código de Cores dos Resíduos Sólidos Recicláveis.

\begin{tabular}{|l|l|}
\hline Cor & Material Reciclável \\
\hline Azul & Papéis/papelão \\
\hline Vermelha & Plástico \\
\hline Verde & Vidros \\
\hline Amarela & Metais \\
\hline Preta & Madeira \\
\hline Laranja & Resíduos perigosos \\
\hline Branca & Resíduos ambulatoriais e de serviços de saúde \\
\hline Marrom & Resíduos orgânicos \\
\hline Cinza & $\begin{array}{l}\text { Resíduo geral não-reciclável ou misturado, ou } \\
\text { contaminado, não passível de separação. }\end{array}$ \\
\hline
\end{tabular}

Verifica-se que a EA está presente em ambas as escolas, contudo os acadêmicos do Colégio $A$ tem uma maior percentagem de acadêmicos que dizem não ter estudado sobre esse assunto, outra questão interessante é não sendo a disciplina de ciências a que possui maior percentagem como sendo a matéria, na qual se viu este conteúdo, perdendo para a disciplina de artes (Figura 6).

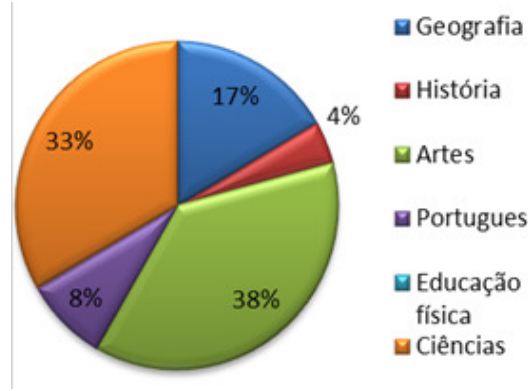

Colégio A

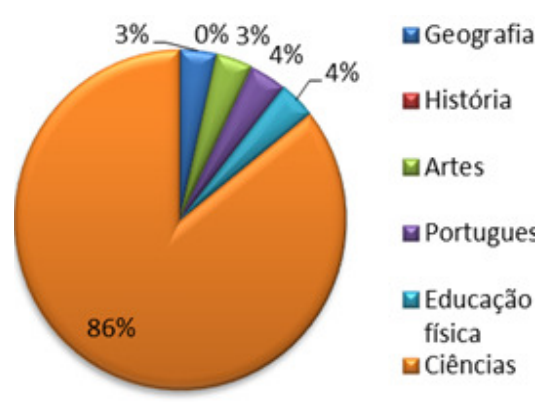

Colégio B

Figura 6: Resposta à Questão 6

Com relação ao Colégio $B$, poucos alunos afirmam não ter estudado a respeito e a disciplina de Ciências se apresenta, como era esperado, na grande maioria dos questionários como a responsável para tratar deste assunto e passar informações a respeito desta temática. 
Apesar de a educação ambiental (EA) na escola ser amplamente defendida não como uma disciplina específica e sim como um tema transversal a ser trabalhado por todas as disciplinas do currículo escolar, na prática ela tem aparecido restritivamente nas disciplinas de Ciências Naturais e Geografia na escola de ensino fundamental e de Biologia e Geografia na escola secundária (FRACALANZA et al., 2005: 04; SORRENTINO, 1997). No ensino de Química, professores consideram que ela é tratada no estudo de chuva ácida, aquecimento global e destruição da camada de ozônio. Nesses estudos, a questão ambiental é vista em termos de processos químicos, todavia, percebese que muito pouca preocupação tem tido por parte da maioria dos professores de Química na busca de uma educação ambiental que esteja comprometida com a formação de atitudes e uma compreensão global de questões socioambientais.

Podemos atribuir, em parte, o desempenho não satisfatório dos alunos em relação à reciclagem devido ao fato das atividades referentes a reciclagem de materiais não ser algo rotineiro nas escolas. Apesar de um grande número de alunos afirmarem ter aprendido Educação Ambiental, a falta de atividades práticas pode estar prejudicando o aprendizado deste conteúdo quando abordado. As crianças não estão diferenciando conceitos.

A última questão referia-se ao que os alunos acharam do questionário. O fato interessante é que $79 \%$ dos acadêmicos acharam as questões fáceis mesmo não atingindo uma boa média nas respostas das questões.

\section{Conclusões}

A avaliação efetuada em escolas do município de Francisco Beltrão, Paraná, com relação ao conhecimento dos acadêmicos a respeito de reciclagem mostrou que o estudo sobre reciclagem ocorre nas escolas contudo, existem alguns pontos que necessitam melhorar como:

A forma com que é abordada a questão da reciclagem se mostra um tanto quanto ineficiente com relação aos conceitos envolvidos na temática.

Existe uma certa dificuldade pelos alunos em definirem que material é ou não reciclável e como realizar a separação.

Devem-se priorizar mais atividades práticas referentes ao tema.

Estas mudanças podem servir para aumentar o conhecimento geral dos acadêmicos com relação a reciclagem de materiais. 


\section{Referências}

ALMEIDA, L.F.R.; BICUDO, L.R.H.; BORGES, G.L.A. Educação ambiental em praça pública: relato de experiência com oficinas pedagógicas. Revista Ciência e Educação. São Paulo, v. 10, n. 1, p. 121-132, 2004.

BRASIL. Ministério da Saúde. ANVISA - Agência Nacional de Vigilância Sanitária. Manual de Gerenciamento dos Resíduos de Serviços de Saúde. Brasília. Ministério da Saúde, 2006, 190 p.

CRISÓSTOMO, A.L. Educação ambiental, reciclagem de resíduos sólidos e responsabilidade social: formação de educadores ambientais. Revista Conexão UEPG, Ponta Grossa, v. 7, n.1, p. 88-95, 2011.

FRACALANZA, H.; AMARAL, I.A.; MEGID NETO, J.M.; EBERLIN, T.S. (2005). A educação ambiental no Brasil: panorama inicial da produção acadêmica. Atas do Encontro Nacional de Pesquisa em Educação em Ciências, Brasil, 2005.

GOMES, D.V. Educação para o consumo ético e sustentável. Revista Eletrônica do Mestrado em Educação Ambiental. v. 16, p. 18-31, janjun/2006.

GRIPPI, S. Lixo, reciclagem e sua história: guia para as prefeituras brasileiras. Rio de Janeiro, Interciência, 2001.

MONTEIRO, J.H.P. et al. Manual de gerenciamento integrado de resíduos sólidos. Rio de Janeiro, IBAM, 2001.

OLIVEIRA, T.C.S. Gestão de resíduos sólidos nas cidades e o modelo cooperativista: estudo de caso da Cooperativa de Reciclagem Boa Esperança de Salto -CORBES. Âmbito Jurídico, Rio Grande, 2009.

REBELLO, L.H.B.; VIEIRA, A.S. A contribuição do design "verde": um estudo de caso da empresa Wöllner. REDIGE. v. 2, n. 1, 2011.

SORRENTINO, M. Vinte anos de Tbilisi, cinco da Rio-92: A Educação Ambiental no Brasil. Debates socioambientais. São Paulo: CEDEC, V.2, n.7, pp.3-5, 1997.

RODRIGUES, H.W.. A educação ambiental no âmbito do ensino superior brasileiro. In: LEITE, J.R.M.; BELLO FILHO, N.B. (org.). Direito ambiental contemporâneo. Revista dos Tribunais. São Paulo, p. 395-409, 2004.

$\mathrm{SCHALCH}$, V. et al. Gestão e gerenciamento de resíduos sólidos. Apostila, USP, São Carlos, 2002, 93 p.

SIRVINSKAS, L.P. Meio ambiente e cidadania. Revista do Instituto de Pesquisas e Estudos. Bauru, n. 35: p. 305-307, ago/2002. 